\title{
A FRAMEWORK FOR THE ANALYSIS OF DUAL LAYER STACKED NOVEL MICROSTRIP PATCH ANTENNA DESIGN EMPLOYING FLEXIBLE SUBSTRATES
}

\author{
Avneet Kaur ${ }^{1}$ and Dr. Ekambir Sidhu ${ }^{2}$
}

\begin{abstract}
This research article proposes a novel double-layered stacked microstrip patch antenna design. The antennas are simulated in four types of flexible antennas with a different dielectric material. The materials used in stacking are low dielectric materials with $\varepsilon_{\mathrm{r}}=2.1$ (Teflon) and $\varepsilon_{\mathrm{r}}=2.7$ (Poly-vinylchloride). It is a probe fed antenna for impedance matching with $50 \Omega$ coaxial cable. The results are compared on the basis of variation of different layers of dielectric constant and some of the antenna parameters for bandwidth analysis. The analysis for the performance of microstrip patch antenna has been evaluated in terms of directivity $(\mathrm{dBi})$, gain $(\mathrm{dB})$, return loss $(\mathrm{dB})$, impedance bandwidth $(\mathrm{GHz})$ and half power beam width (degrees). The proposed antenna operates for acceptable voltage standing wave ratio (VSWR) less than two. A wide band characteristic of stacked rectangular microstrip antenna is experimentally studied and designed in CST Microwave Studio 2014.

Keywords: Double layer Stacking, Flexible antenna, Polyvinylchloride, Reduced ground surface, Teflon.
\end{abstract}

\section{INTRODUCTION}

Presently, a lot of investigation is being done on antennas. Enormous research work is currently being done on patch/microstrip antennas [1]. Microstrip antennas are extensively used in the microwave frequency region [2]. The recompenses of the microstrip patch antennas are small size, low profile, and lightweight, conformable to planar and non-planar surfaces [3,4]. Microstrip antennas are wide in impedance bandwidth and low in cross polarization level. But as we are well aware of the fact that the technology is ubiquitously getting advanced mostly on a daily basis, so there is a need of high efficiency in all communication fields. Conventional antennas have limitations in hostile military environment or biomedical sectors [5]. Over the recent years, there has been an upsurge in the growth of flexible electronics, such as flexible displays, smart tags, and wearable products. The flexible printed circuit boards (PCBs) have become an essential component of transferrable wireless applications [6]. Flexible materials can be moulded in any shaped for better results for example in mobile phones, cars, robots, human body, buildings and many more. The competence of flexible systems mostly depends on the features of the integrated antenna [7].

Microstrip patch antennas are extensively used for wireless applications. For most satellite communication systems, the operating bandwidth of the systems lies in the frequency range from 12 to $18 \mathrm{GHz}$, which is commonly known as the Ku-band. Predominantly, the satellite communication systems are used in satellite TV; Fixed Satellite Systems (FSS); VSAT system; Direct Broadcast Satellite (DBS); Broadcasting Satellite (BSS); Marine communication. The $\mathrm{Ku}$ band is also used for satellite altimetry and high resolution mapping. The utmost usage of the $\mathrm{Ku}$ Band lies in the field of tracking the satellite within the ranges roughly from $12.87 \mathrm{GHz}$ to $14.43 \mathrm{GHz}$ [8]. As demonstrated by INTELSAT, FSS has been one of the most fruitful part of commercial satellite communications. The earlier applications of FSS were major trunking applications and point-to-point telephony. Plentiful sorts of patch antennas have been ascertained and inspected by several investigators due to their exceptional properties. The Microstrip patch antennas utilize the monopole configuration such as annual ring, triangle, ring, elliptical, circular disc, hexagonal and pentagonal antennas, the dipole configuration like bow-tie antennas. In satellite Communications, circularly polarized radiation patterns are required using an either a rectangular or circular patch [9-10].

The main goal of this research is to inspect and evaluate the performance of two layer stacked microstrip patch antenna employing two different low dielectric materials, that is, Teflon $\left(\varepsilon_{\mathrm{r}}=2.1\right)$ and Polyvinylchloride $\left(\varepsilon_{\mathrm{r}}=\right.$

\footnotetext{
${ }^{1}$ Department of Electronics and Communication Engineering, Punjabi University, Patiala.

${ }^{2}$ Department of Electronics and Communication Engineering, Punjabi University Patiala, India
} 
2.7). The performance has been analysed in terms of gain, directivity, HPBW, VSWR and bandwidth. The paper has been organized as follows: The geometry and analysis of the antenna has been discussed in section II, followed by simulated results in section III and at last, conclusion in section IV.

\section{GEOMETRY OF THE ANTENNA}

The novel design of flexible double layer stacked microstrip patch antenna has been designed and simulated using the CST (Computer Simulation Technology) Microwave Studio 2014. This paper proposes four types of microstrip patch antennas constructed on flexible substrates. The antenna has been fabricated using stacking of two different substrates, that is, Teflon and Polyvinylchloride with dielectric constant of 2.1 and 2.7, respectively. The height of lower substrate and that of upper substrate is $1 \mathrm{~mm}$. The defected ground has been designed at the bottom of the lower stack. The proposed antenna geometry is analysed in six ways and they are-: by placing Teflon on top of PVC substrate,

by placing PVC over Teflon substrate,

by taking Teflon substrate of thickness $2 \mathrm{~mm}$,

and by taking PVC substrate of thickness $2 \mathrm{~mm}$,

by placing Teflon and PVC horizontally type A and,

by placing Teflon and PVC horizontally type B

In this paper, substrate, structure materials and patch design employed in the antenna designs have been retained identical, whereas the antenna designs are distinctive. The wide band microstrip patch antenna has a radiating patch of wind mill shaped and defected ground of thickness $0.05 \mathrm{~mm}$. The radiating patch, lossless feedline and ground plane are made up of copper material of thickness $0.05 \mathrm{~mm}$. The fig.1(a) shows the side view of the substrate. In order to transfer maximum power to the radiating patch, the feedline is connected directly to the patch. The fig. 1(b) portrays the top view of the double stacked MPA on the radiating patch. The bottom view of the proposed antenna with reduced ground structure is shown in fig. 1(c). The dimensions of the radiating patch, substrate, reduced ground and the feed line have been listed in Table I. Microstrip type antennas need aground plane on the opposite side of the substrate for electromagnetic waves to travel along the feed line.

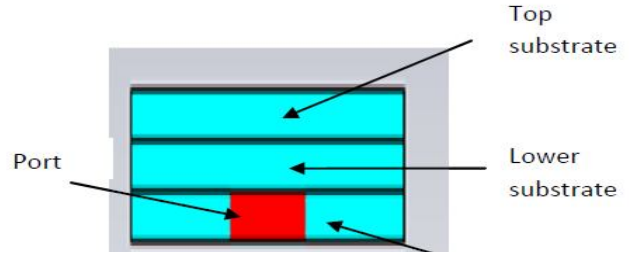

Fig.1 (a) Side view of the proposed antenna design

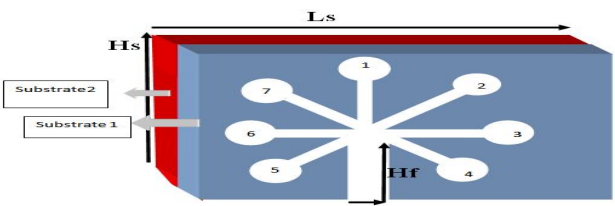

Fig.1 (c) Top view of the proposed antenna design
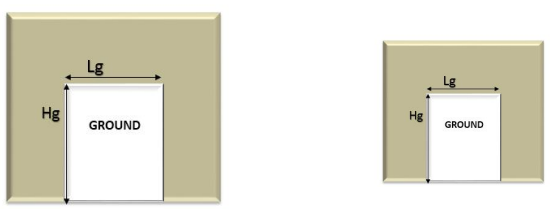

Fig. 1(b) Bottom view of the proposed antenna

\section{SIMULATED RESULTS}

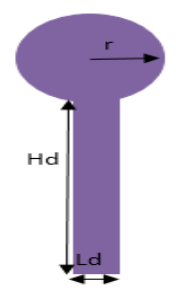

Fig.1 (d) Dimensions of each circle in the patch of the proposed antenna design

Table I. ANTENNA DIMENSIONS

\begin{tabular}{|l|l|l|}
\hline Antenna Dimensions & Description & $\begin{array}{l}\text { Value } \\
(\mathbf{m m})\end{array}$ \\
\hline $\mathrm{L}$ & Length of substrate & 60 \\
\hline $\mathrm{H}$ & Height of substrate & 60 \\
\hline $\mathrm{T}$ & Total thickness of antenna & 2.05 \\
\hline $\mathrm{Tp}$ & Thickness of patch & 0.05 \\
\hline $\mathrm{Ts}$ & Thickness of substrate & 2 \\
\hline $\mathrm{Tg}$ & Thickness of ground & 0.05 \\
\hline $\mathrm{Hg}$ & Height of ground & 38.5 \\
\hline $\mathrm{Lg}$ & Length of ground & 28 \\
\hline $\mathrm{Hs}$ & Height of substrate & 60 \\
\hline $\mathrm{Ls}$ & Height of substrates & 60 \\
\hline $\mathrm{Hd}$ & Height of stride to circle & 54 \\
\hline $\mathrm{r}$ & Radius of the circle & 5 \\
\hline $\mathrm{Ld}$ (for circle 1,6,3) & Length of stride to circle & 1.5 \\
\hline $\mathrm{Ld}$ (for circle 2,4,5,7) & Length of stride to circle & 1.8 \\
\hline $\mathrm{Lf}$ & Length of feedline & 9 \\
\hline $\mathrm{Hf}$ & Height of feedline & 30 \\
\hline & &
\end{tabular}

The proposed 3-D flexible patch antenna has been simu technology) Microwave Studio 2014. A thorough parametric study of the designed antenna has been carried out in terms of return loss, impedance bandwidth, gain, directivity, VSWR and antenna impedance. The proposed antenna geometry is analysed in six ways and they are-: 
1. i) By stacking the two substrates vertically A (Teflon being the upper layer and PVC being the lower layer in the stacking of the substrates)

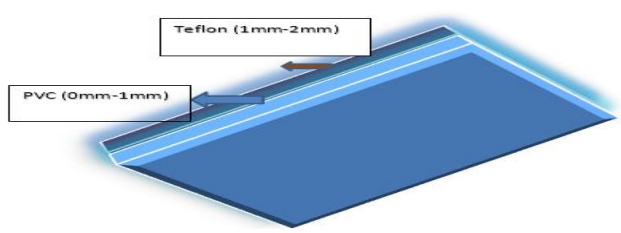

Fig. 2(a) Side view of the proposed antenna design

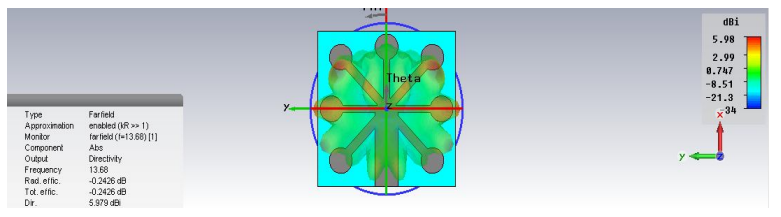

Fig. 2(c) Gain plot of the proposed antenna design

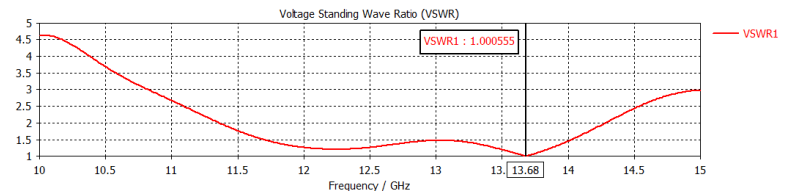

Fig. 2(e) VSWR plot of the proposed antenna design

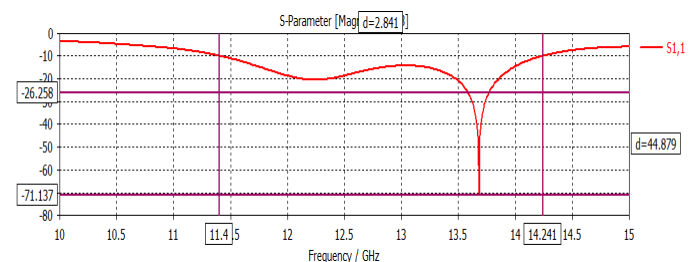

Fig. 2(b) Return loss (S11) plot of the proposed antenna design

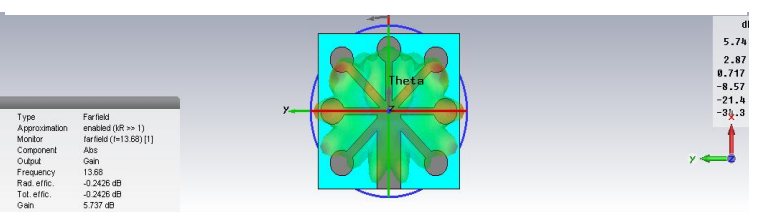

Fig. 2(d) Directivity plot of the proposed antenna design

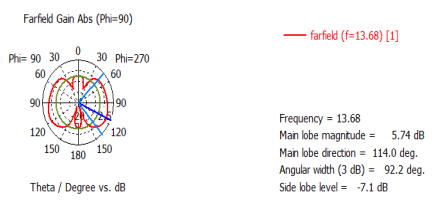

Fig. 2(f) HPBW plot of the proposed antenna design

The proposed wide band antenna has impedance bandwidth of $2.841 \mathrm{GHz}$ with operating frequency range of $11.4 \mathrm{GHz}-14.241 \mathrm{GHz}$ at resonating frequency $13.68 \mathrm{GHz}$ as shown in fig. $2(\mathrm{~b})$. The return loss $\left(\mathrm{S}_{11}\right)$ plot of the antenna design at $13.68 \mathrm{GHz}$ is observed to be $-71.137 \mathrm{~dB}$. The gain and directivity of the vertically stacked microstrip patch antenna is observed to be $5.373 \mathrm{~dB}$ and $5.979 \mathrm{dBi}$, respectively. The VSWR vs frequency plot is shown in figure 2(e), which clearly shows that the VSWR lies below 2 within the operating frequency range. The coaxial probe feeding is agreed at a specific site of the point where input impedance is approximately $50 \Omega$. The half power beam width (HPBW) for resonant frequency at $13.68 \mathrm{GHz}$ is accounted to be 92.2 degree as shown in fig. 2(f).

ii) By placing the stacking vertically B (PVC being the upper layer and Teflon being the lower layer in the stacking of the substrates)

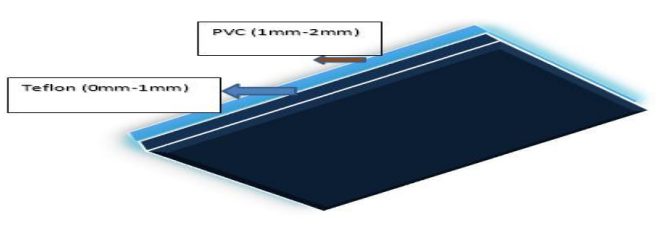

Fig. 3(a) Side view of the proposed antenna design
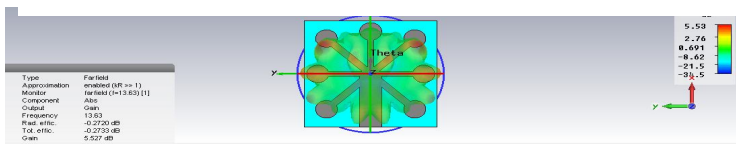

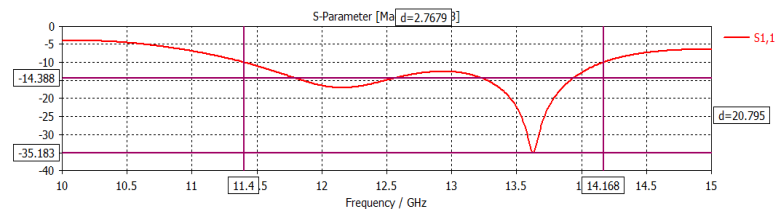

Fig. 3(b) Return loss (S11) plot of the proposed antenna design

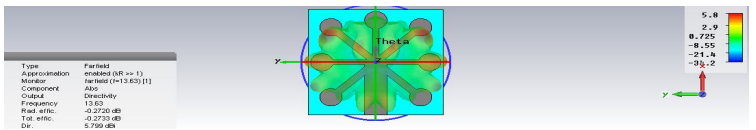

Fig. 3(d) Directivity plot of the proposed antenna design 

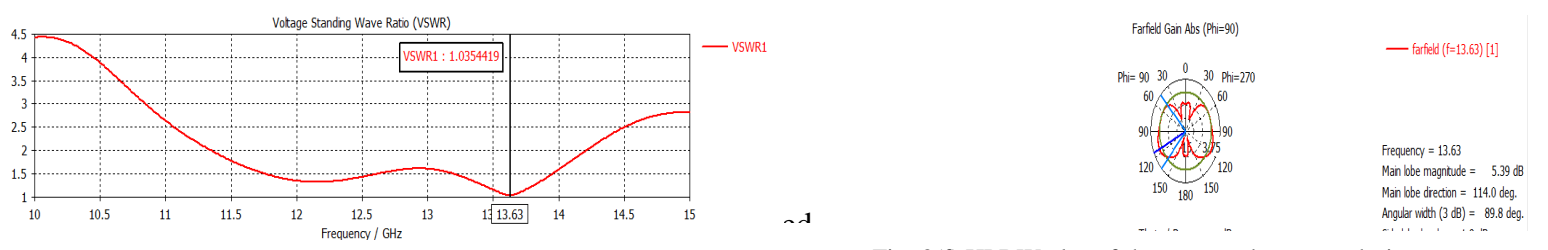

1. Fig. 3(f) HPBW plot of the proposed antenna design

is accounted to be $5.799 \mathrm{dBi}$. The proposed wide band antenna has impedance bandwidth of $2.7679 \mathrm{GHz}$ with operating frequency range of $11.4 \mathrm{GHz}-14.168 \mathrm{GHz}$ at resonating frequency $13.63 \mathrm{GHz}$ as shown in fig. 3(b). The return loss $\left(S_{11}\right)$ plot of the antenna design at $13.68 \mathrm{GHz}$ is observed to be $-35.183 \mathrm{~dB}$. The VSWR and HPBW plot has been depicted in fig. 3(e) and 3(f), from which it is observed that VSWR has its value below than maximum acceptable value 2 and HPBW is measured to be 89.8 degree.

2.

i) By stacking the same material twice (Teflon)

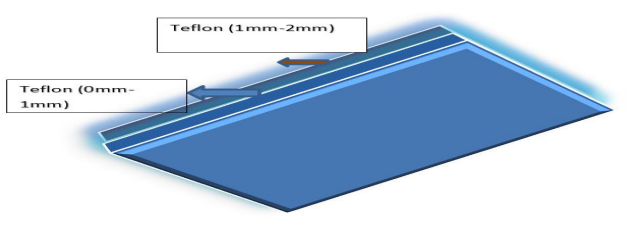

Fig. 4(a) Side view of the proposed antenna

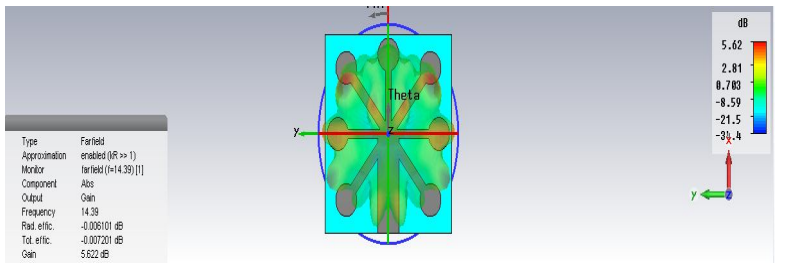

Fig 4(c) Gain of the proposed antenna

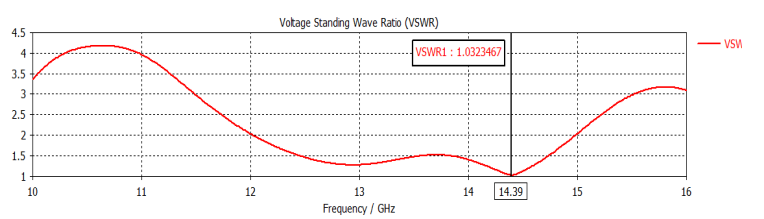

Fig. 4(e) VSWR plot of the proposed antenna

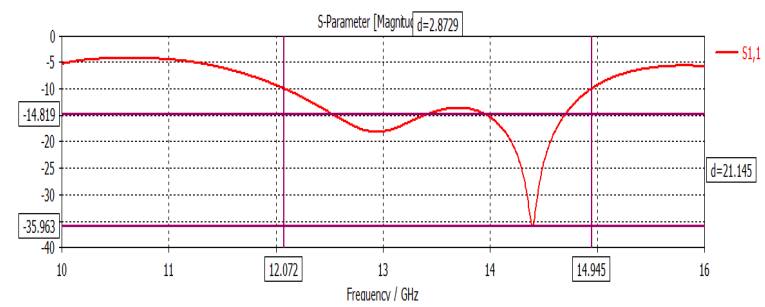

Fig. 4(b) Return loss (S11) plot of the proposed antenna design

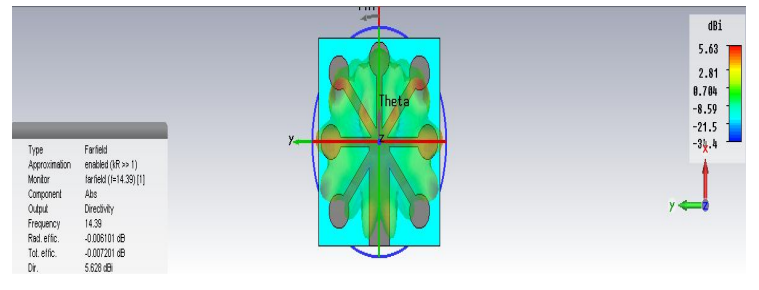

Fig 4(d) Directivity of the proposed antenna

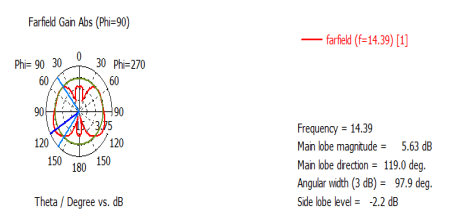

Fig. 4(f) HPBW plo tof proposed antenna

The proposed antenna has impedance bandwidth of $2.8729 \mathrm{GHz}$ with operating frequency range of $12.072 \mathrm{GHz}-$ $14.945 \mathrm{GHz}$ at resonating frequency $14.39 \mathrm{GHz}$ as shown in fig. $4(\mathrm{~b})$. The return loss $\left(\mathrm{S}_{11}\right)$ plot of the antenna design at $14.39 \mathrm{GHz}$ is observed to be $-35.963 \mathrm{~dB}$. The gain and directivity of the microstrip patch antenna is observed to be $5.622 \mathrm{~dB}$ and $5.979 \mathrm{dBi}$, respectively. The VSWR vs frequency plot is shown in figure 4(e), which clearly shows that the VSWR lies below 2 within the operating frequency range. The half power beam width (HPBW) for resonant frequency at $14.39 \mathrm{GHz}$ is accounted to be 97.9 degree as shown in fig. 4(f).

ii) By stacking the same material twice (PVC)

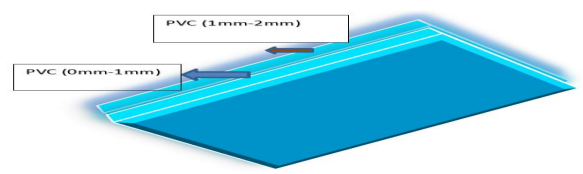

Fig. 5(a) Side view of the proposed antenna

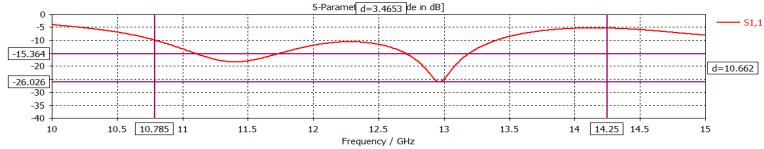

Fig. 5(b) Return loss (S11) plot of the proposed antenna design 


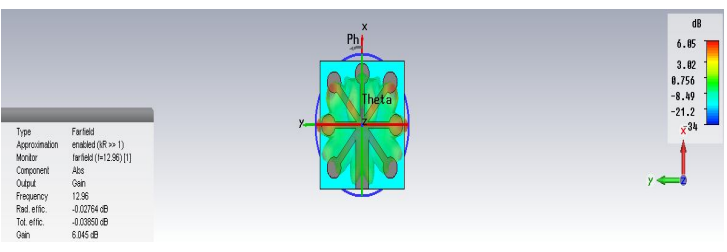

Fig. 5(c) Gain plot of the proposed antenna design

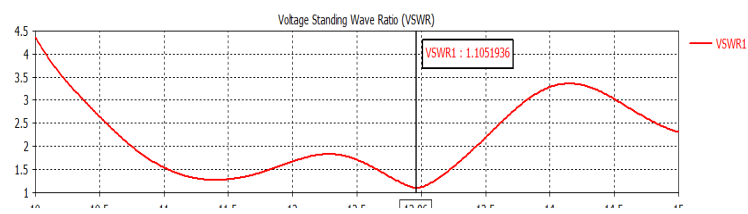

Fig. 5(e) VSWR plot of the proposed antenna design

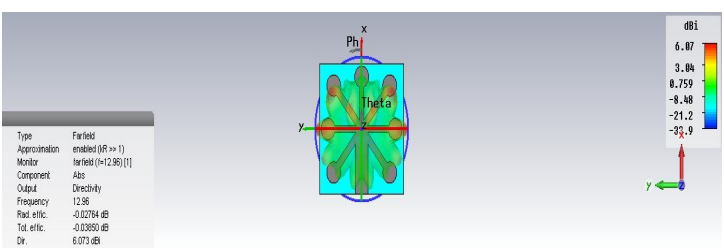

Fig. 5(d) Directivity plot of proposed antenna design

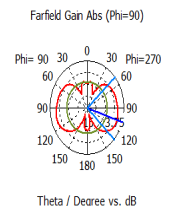

— farfeld (ff=12.96) [1]

Frequency $=12.96$ Man boe magnitude $=6.06 \mathrm{~dB}$ Angular width $(3 \mathrm{~dB})=83.9 \mathrm{deg}$. Sde bbe evel $=-7.1 \mathrm{~dB}$

The gain and directivity plot has been depicted in fig. 5(c) and 5(d), which is measured to be $6.045 \mathrm{~dB}$ and $6.073 \mathrm{dBi}$, respectively. The proposed wide band antenna has impedance bandwidth of $3.4653 \mathrm{GHz}$ with operating frequency

range of $10.785 \mathrm{GHz}-14.25 \mathrm{GHz}$ at resonating frequency $12.96 \mathrm{GHz}$ as shown in fig. $2(\mathrm{~b})$. The return loss $\left(\mathrm{S}_{11}\right)$ plot of the antenna design at $13.68 \mathrm{GHz}$ is observed to be $-26.026 \mathrm{~dB}$. The VSWR and HPBW plot has been depicted in fig. 5(e) and 5(f), from which it is observed that VSWR has its value below than maximum acceptable value 2 and HPBW is measured to be 83.9 degree.

3. i) Horizontal stacking $A$
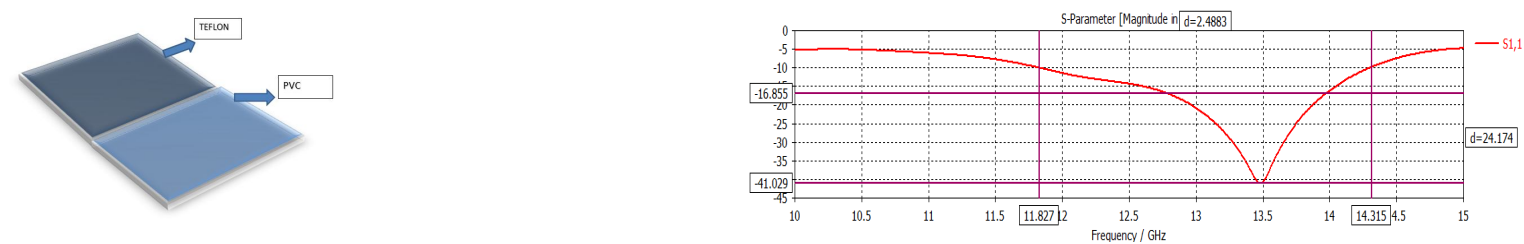

Fig. 6(a) Side view of the proposed antenna design

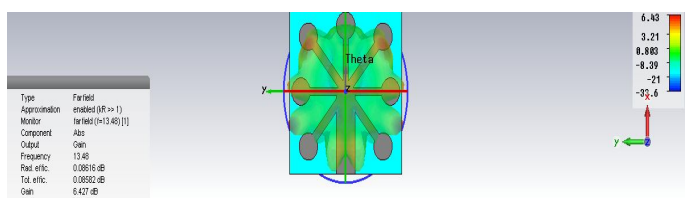

Fig. 6(c) Gain of the proposed antenna design

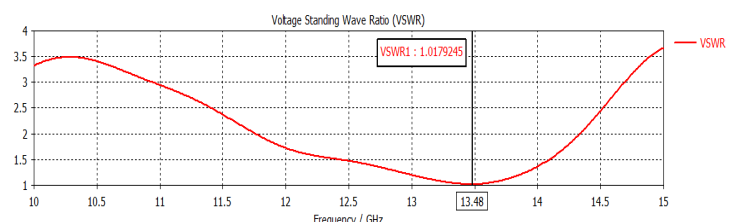

Fig. 6(e) VSWR of the proposed antenna design
Fig. 6(b) Return loss (S11) plot of the proposed antenna design

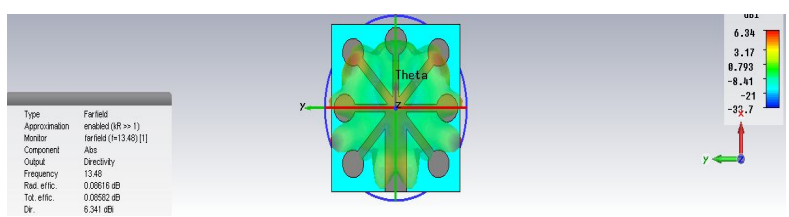

Fig. 6(d) Directivity of the proposed antenna design

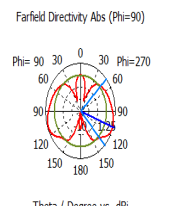

一 farfied (f=13.48) [1]

Frequency $=13.48$

Main bbe magniude $=4.52$ d Man bbe diretion $=110.0$ deg.
Angular with $(3 \mathrm{AB})=894 \mathrm{deg}$ Side bbe evel $=-3.2 \mathrm{~dB}$

Fig. 6(f) HPBW of the proposed antenna design 
The proposed dual layer stacked antenna has impedance bandwidth of $2.4883 \mathrm{GHz}$ with operating frequency range of $11.827 \mathrm{GHz}-14.315 \mathrm{GHz}$ at resonating frequency $13.48 \mathrm{GHz}$ as shown in fig. $6(\mathrm{~b})$. The return loss $\left(\mathrm{S}_{11}\right)$ plot of the antenna design at $13.48 \mathrm{GHz}$ is been observed to be $-41.029 \mathrm{~dB}$. The gain and directivity of the horizontally stacked microstrip patch antenna is been observed to be $6.427 \mathrm{~dB}$ and $6.341 \mathrm{dBi}$, respectively. The figure 6(e) clearly shows that the VSWR lies below 2 within the operating frequency range. The half power beam width (HPBW) for resonant frequency at $13.48 \mathrm{GHz}$ is accounted to be 89.4 degree as shown in fig. 6(f).

ii) By horizontal Stacking B

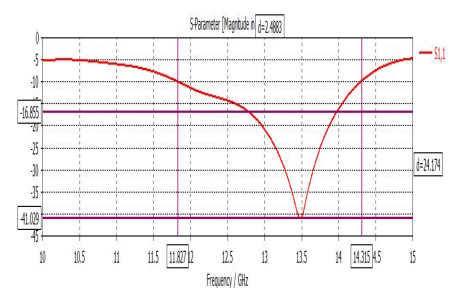

Fig. 7(a) Side view of the proposed antenna design

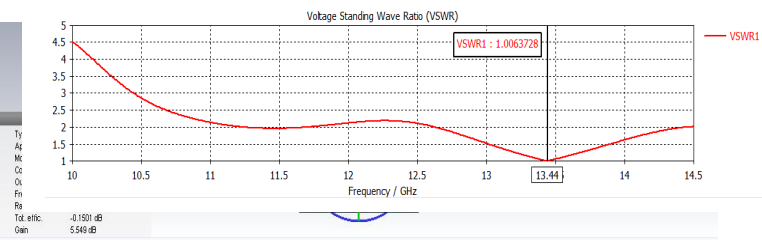

Fir $7(0)$ Sain of the nronoced antenna decion

Fig. 7(e) VSWR of the proposed antenna design

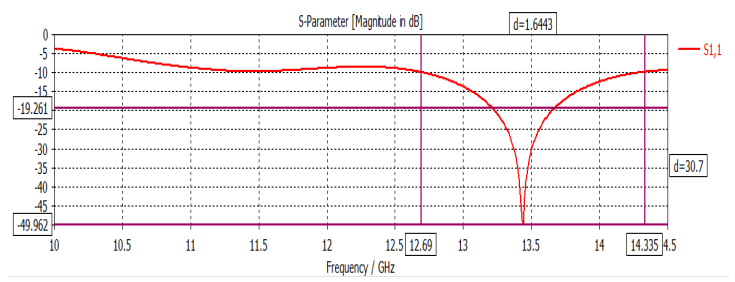

Fig. 7(b) Return loss (S11) plot of the proposed antenna design

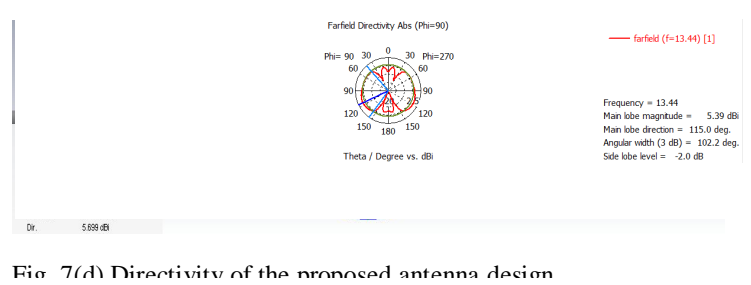

Fig. 7(f) HPBW of the proposed antenna design

The proposed dual layer stacked antenna has impedance bandwidth of $1.6443 \mathrm{GHz}$ with operating frequency range of $12.69 \mathrm{GHz}-14.335 \mathrm{GHz}$ at resonating frequency $12.44 \mathrm{GHz}$ as shown in fig. $7(\mathrm{~b})$. The return loss $\left(\mathrm{S}_{11}\right)$ plot of the antenna design at $12.44 \mathrm{GHz}$ is observed to be $-49.961657 \mathrm{~dB}$. The gain and directivity of the horizontally stacked microstrip patch antenna is observed to be $5.549 \mathrm{~dB}$ and $5.699 \mathrm{dBi}$, respectively. The figure 7(e) clearly shows that the VSWR lies below 2 within the operating frequency range. The half power beam width (HPBW) for resonant frequency at $12.44 \mathrm{GHz}$ is accounted to be 102.2 degree as shown in fig. 7(f).

\begin{tabular}{|c|c|c|c|c|c|c|}
\hline PARAMETER & $\begin{array}{l}\text { VERTICALLY } \\
\text { STACKED (A) }\end{array}$ & $\begin{array}{l}\text { VERTICALLY } \\
\text { STACKED (B) }\end{array}$ & $\begin{array}{l}\text { HORIZONTALLY } \\
\text { STACKED (A) }\end{array}$ & $\begin{array}{l}\text { HORIZONTALLY } \\
\text { STACKED (B) }\end{array}$ & TEFLON & PVC \\
\hline $\begin{array}{l}\text { Total thickness of } \\
\text { substrate }\end{array}$ & $2 \mathrm{~mm}$ & $2 \mathrm{~mm}$ & $1 \mathrm{~mm}$ & $1 \mathrm{~mm}$ & $2 \mathrm{~mm}$ & $2 \mathrm{~mm}$ \\
\hline $\begin{array}{l}\text { Thickness of Teflon } \\
\text { Substrate }\end{array}$ & $1 \mathrm{~mm}$ & $1 \mathrm{~mm}$ & $1 \mathrm{~mm}$ & $1 \mathrm{~mm}$ & $2 \mathrm{~mm}$ & $0 \mathrm{~mm}$ \\
\hline $\begin{array}{l}\text { Thickness of PVC } \\
\text { substrate }\end{array}$ & $1 \mathrm{~mm}$ & $1 \mathrm{~mm}$ & $1 \mathrm{~mm}$ & $1 \mathrm{~mm}$ & $0 \mathrm{~mm}$ & $2 \mathrm{~mm}$ \\
\hline Bandwidth(Ghz) & 2.841 & 2.7679 & 2.4883 & 11.6443 & 2.872 & 3.465 \\
\hline $\begin{array}{l}\text { Resonant } \\
\text { Frequencies(Ghz) }\end{array}$ & 13.68 & 13.63 & 13.48 & 12.44 & 14.39 & 12.96 \\
\hline VSWR & 1.000 & 1.035 & 1.017 & 1.06 & 1.032 & 1.105 \\
\hline Gain (dB) & 5.373 & 5.527 & 6.427 & 5.549 & 5.622 & 6.045 \\
\hline Directivity (dBi) & 5.979 & 5.799 & 6.341 & 5.699 & 5.979 & 6.073 \\
\hline Return Loss (dB) & -71.137 & -35.183 & -41.029 & -49.961657 & -35.963 & -26.026 \\
\hline HPBW & 92.2 & 89.8 & 89.4 & 102 & 97.9 & 83.9 \\
\hline Bandwidth percentage & 22.16 & 21.65 & 19.03 & 12.16 & 21.26 & 27.68 \\
\hline
\end{tabular}




\begin{tabular}{|c|c|c|c|c|c|c|}
\hline Applications $^{13}$ & $\begin{array}{l}\text { FSS Earth } \\
\text { Stations, Active } \\
\text { Sensors, Maritime } \\
\text { Radar, and } \\
\text { Radiolocation(mili } \\
\text { tary) }\end{array}$ & $\begin{array}{l}\text { FSS Earth Stations, } \\
\text { Active Sensors, and } \\
\text { Maritime Radar }\end{array}$ & $\begin{array}{l}\text { FSS Earth Stations, } \\
\text { Active Sensors, } \\
\text { Maritime Radar, } \\
\text { Space Research and } \\
\text { Radio Navigation }\end{array}$ & $\begin{array}{l}\text { FSS Earth Stations, } \\
\text { Active Sensors, } \\
\text { Maritime Radar, } \\
\text { Space Research and } \\
\text { Radio Navigation }\end{array}$ & $\begin{array}{l}\text { FSS Earth } \\
\text { Stations, } \\
\text { Active } \\
\text { Sensors, } \\
\text { Maritime } \\
\text { Radar and } \\
\text { Defense } \\
\text { System }\end{array}$ & $\begin{array}{l}\text { FSS } \\
\text { Earth } \\
\text { Station } \\
\text { s, } \\
\text { Defens } \\
\text { e } \\
\text { System } \\
\text { Broadc } \\
\text { asting } \\
\text { (Satelli } \\
\text { te) and } \\
\text { Radio } \\
\text { Astron } \\
\text { omy. }\end{array}$ \\
\hline
\end{tabular}

\section{CONCLUSION}

The proposed flexible microstrip patch antenna has been designed and simulated using the CST (Computer Simulation Technology) Microwave Studio 2014. The proposed flexible flanged antenna has substrate thickness $2.00 \mathrm{~mm}$ and copper thickness of $0.05 \mathrm{~mm}$. The substrate materials used are Teflon, PVC with dielectric constant 2.1 and 2.7, respectively. From the above discussion, it has been concluded that between horizontal stacking A and horizontal stacking B, Horizontal stacking A is more proficient in terms of bandwidth, VSWR, gain and directivity. By comparing vertical stacking A and vertical stacking B from Table II, we can observe that, vertical stacking A is superior in terms of bandwidth, VSWR, Directivity, Return loss and HPBW. When stacking the same material twice, the thickness of the material doubles hence when looking into the antenna parameters and analyzing the performance of Teflon and Polyvinylchloride material, we can observe from Table II that PVC material has wide bandwidth, high Gain and Directivity in comparison to the Teflon material for this particular antenna design.

\section{ACKNOWLEDGMENT}

We would like to thank Prof. Ekambir Sidhu, Assistant professor, Department of Electronics and Communication Engineering, Punjabi University, Patiala for his supervision and assistance in completing this research work. We would also like to thank our parents and friends for their moral and motivational support.

\section{REFERENCES}

[1] B. D. Patel, Tanisha Narang1, Shubhangi Jain," Microstrip Patch Antenna- A Historical Perspective of the Development," Conference on Advances in Communication and Control Systems 2013 (CAC2S 2013)

[2] Indrasen Singh, Dr. V.S. Tripathi , "Micro strip Patch Antenna and its Applications: a Survey,” International Journal of Circuit Theory and Applications, vol. 2, no. 5, ISSN:2229-6093, Sept.-Oct., 2011.

[3] Pavan Kumar Sharma, Veerendra Singh Jadaun," Multi-Band Rectangular Microstrip Patch Antenna with Defected Ground Structure and a Metallic Stripm" International Journal of Technological Exploration and Learning (IJTEL) vol. 1, Issue 1, ISSN: 2319-2135, August 2012.

[4] Stephy john , Manoj k c," Microstrip Patch Antennas for Uwb Applications: A Review ," IOSR Journal of Electronics and Communication Engineering (IOSR-JECE), vol. 9, Issue 2, pp- 34-37, Mar - Apr 2014.

[5] Jobin Kurian, Upama Rajan M.N, Shinoj K. Sukumaran, "Flexible Microstrip Patch Antenna using Rubber Substrate for WBAN Applications," International Conference on Contemporary Computing and Informatics (IC3I), 2014.

[6] C. Balanis, Antenna Theory Analysis and Design. New York: Wiley Interscience, 2005.

[7] Rameez Shamalik, Sushama Shelke, "Design and Simulation of Flexible Antenna for ISM band," International Journal of Engineering Research and Applications (IJERA), ISSN: 2248-9622, vol. 2, Issue 3, pp.2168-2170, 2012.

[8] Hirohide Serizawa and Kohei Hongo,"Radiation from a Flanged Rectangular Waveguide," IEEE Transactions on Antennas and Propagation, vol. 53, no. 12, December, 2005.

[9] A. Zvyagintsev, A. Ivanov,"Radiation Pattern Calculation Of Flanged Reflector Antennas," 12th International Conference on Mathematical Methods in Electromagnetic Theory June 29 - July 02, 2008, Odesa, Ukraine.

[10] T. Durga Prasad, K. V. Satya Kumar, MD Khwaja Muinuddin, Chisti B.Kanthamma, V.SantoshKumar," Comparisons of Circular and Rectangular Microstrip Patch Antennas," International Journal of Communication Engineering Applications-IJCEA, vol. 02, Issue 04; July 2011, ISSN: 2230-8520; e-ISSN-2230-8539.

[11] The european table of frequencyallocations and applications in thefrequency range $8.3 \mathrm{khz}$ to $3000 \mathrm{ghz}$ (eca table) 